\title{
UPAYA MENINGKATKAN KETERAMPILANMENULIS TEKS DESKRIPSI MENGGUNAKAN MODEL PEMBELAJARAN DISCOVERY LEARNING PADA SISWA KELAS VII-C SMPNEGERI 3 PANCUR BATU TAHUN PELAJARAN 2018/2019
}

\author{
Oleh : \\ Yohana Sitohang ${ }^{1)}$, Dian Syahfitri ${ }^{2)}$, dan Panigoran Siburian ${ }^{3)}$ \\ Universitas Prima Indonesia, Medan ${ }^{1,2,3)}$ \\ E-Mail : \\ yohanasitohang88@gmail.com ${ }^{1)}$, diansyahfitri@unprimdn.ac.id ${ }^{2)}$, \\ panigoransiburian@ymail.com ${ }^{3)}$
}

\begin{abstract}
The ability of description text writing is a competency that must be achieved in K.D 4.12. This research aims at improving writing skills by applying discovery learning model on students class VII-C of SMPN 3 Pancur Batu based on the result of classroom action research conducted in 2 cycles. This can be seen from the activities of students in the learning process which increasingly improves in each cycle in the first cycle an average of $63.33 \%$ and learning completeness isas many as $36.37 \%$ and increasing in the second cycle is obtained by an average of $87.67 \%$ and Learning condition is as many as $13.33 \%$. It can be said that cycle II run very good. There has been an increase in the results of the description text writing skills because it gained a significant increase of 63 to 81. In this activity, the students did the followings: (1) observing activities, (2) finding activities, (3) asking activities, (4) trying activities, (5) communication activities. Based on the results of the above assessment conducted by the teacher, including attitude competency assessment with direct observation techniques, knowledge competency assessment with written test techniques in the form of describing an object in the first cycle and then in the second cycle the written test returns a description question.
\end{abstract}

Keywords: Ability, Writing, Text, Description, Discovery Learning

\section{PENDAHULUAN}

Pembelajaran merupakan proses pendidikan yang memberikan kesempatan kepada peserta didik untuk mengembangkan potensi mereka menjadi kemampuan yang berkompeten, baik aspek sikap, pengetahuan dan keterampilan dalam menulis. Kegiatan menulis merupakan bagian yang tak terpisahkan dalam seluruh proses belajar yang dialami oleh siswa. Karena kegiatan menulis mempunyai banyak keuntungan, yaitu dengan menulis kegiatan menulis kita dapat mengembangkan berbagai gagasan. Kegiatan menulis memaksa kita lebih banyak menyerap,mencari, serta menguasai informasi sehubungan dengan topik yang kita tulis. Berdasarkan pengamatan penulis selama Program Pengalaman Lapangan dan wawancara dengan guru bidang studi Bahasa Indonesia kelas VII SMP Negeri 3 Pancur Batu, masih banyak siswa yang belum mampu menulis.Hal tersebut dikarenkan pembelajaran menulis lebih banyak disajikan dalam bentuk teori, tidak banyak melakukan praktik menulis.Keadaan dilapangan juga menujukkan bahwa kemampuan siswa dalam menerima dan membangun pengetahuan yang baru dan 
pengalamannya sesuai materi pembelajaran masih rendah.Para guru hanya memberikan penugasan atau latihan kepada siswa tanpa menggunakan media ataupun model yang kurang tepat.Dan mengakibatkan siswa minat siswa merasa bosan dengan keterampilan menulis sehinggat siswa kurang meminati menulis dalam bentuk imajinasi dan kurangnya motivasi dari guru kepada siswa.

Peniliti mendapatkan kesimpulan bahwa proses pembelajaran yang dilakukan guru cenderung berceramah dalam menyampaikan materi kepada siswanya kepada siswa maka dari itu, kemampuan siswa dalam hal menulis belum memenuhi harapan guru dan belum mencapai nilai KKM yang telah ditentukan sekolah yaitu 70 .

Model pembelajaran yang dapat meningkatkan kemampuan menulis karangan, salah satu satunya melalui model discovery learning, Human berpendapat bahwa model discovery learning adalah model pembelajaran untuk mengembangkan cara belajar siswa aktif dengan menemukan sendiri,menyelediki sendiri, maka hasil yang diperolekan setia dan tahan lama dan tahan lama dalam ingatan,tidak akan mudah dilupakan. Sedangkan (Djuanda 1997:35) berpendapat bahwa menulis dan mengarang memiliki proses yang sama, yakni melahirkan gagasan, pikiran, perasaan dan pendapat kepada orang lain ataupun pada dirinya sendiri melalui media tulisan.

Teks deskripsi merupakan teks yang mendesdkripsikan suatu objek yang sudah ditentukan sebagai salah satu saran dengan potensi yang tinggi didalam melatih pengerahuan kita. Melalui pembelajaran ini deskripsi siswa diharapkan dapat mengembangkan kemampuan menulis dan mendeskripsikan.

\section{METODE PENELITIAN}

Tempat dan Waktu

Penelitian ini dilaksanakan di SMP Negeri 3 Pancur Batu kelas VII-C Tahun pelajaran 2018/2019 dan dilaksanakan pada semester genap Tahun Pelajaran 2018/2019.

\section{Pendekatan Penelitian}

Pendekatan penelitian merupakan cara ilmiah untuk mendapatkan data dengan tujuan dan kegunaan tertentu. Penelitian ini dilakukan dengan menggunakan Penelitian Tindakan Kelas (PTK).

\section{Subjek dan Objek Penelitian}

Subjek penelitian ini adalah siswa kelas VII-C SMP Negeri 3 Pancur Batu Tahun Pelajaran 2018/2019 yang berjumlah 30 siswa.

Objek penelitian ini adalah penerapan model pembelajaran discovery learning untuk meningkatkan kemampuan menulis teks deskripsi pada kelas VII-C SMP Negeri 3 Pancur Batu 2018/2019.

\section{Data dan Sumber Data}

Data adalah segala fakta dan angka yang dapat dijadikan bahan untuk menyusun suatu informasi dalam bentuk semua laporan penelitian. Adapun data yang digunakan dalam penelitian ini adalah kualitatif.Pengambilan data dilakukan di ruangan kelas VII-C SMP Negeri 3 Pancur Batu tahun pelajaran 2018/2019.

Sumber data diperoleh dari hasil wawancara, hasil tes belajar siswa pada pokok pembahasan teks deskripsi pada mata pelajaran Bahasa Indonesia melalu model discovery learning.

\section{Teknik Pengumpulan Data}

\section{Wawancara}

Wawancara atau interview adalah suatu metode atau cara yang digunakan untuk mendapatkan jawaban dari responden dengan jalan Tanya jawab sepihak 
2. Observasi Pengamatan

Observasi adalah kegiatan pengamatan (pengambilan data) untuk memotret seberapa jauh efek tindakan telah mencapai sasaran.

3. Tes

Menurut Arikunto (2013:193) tes adalah seserentetan pertanyaan atau latihan serta alat lain yang digunakan untuk mengukur keterampilan, pengetahuan intelegensi kemampuan atau bakat yang dimiliki oleh individu atau kelompok.

\section{Dokumentasi}

Arikunto (2014:201) menjelaskan bahwa dokumentasi berasal dari kata dokumen, yang artinya barangbarang tertulis seperti buku-buku, peraturan, cacatan harian. Dokumentasi bias berbentuk tulisan, gambar, atau karya-karya dari seseorang.

\section{Indikator Kinerja}

Indikator kinerja yaitu tolak ukur untuk mengukur dan menentukan keberhasilan yang ditentukan oleh SMP Negeri 3 Pancur Batu adalah sebagai berikut: "Apabila nilai kriteria ketuntasan minimal (KKM) keterampilan menulis dalam teks deskripsi $\geq 70$ dan nilai kriteria ketuntasan klaksikan (KKK) $75 \%$ dari jumlah siswa".

\section{Tabel 1 Rekapitulasi Peningkatan Hasil Nilai Tes Kemampuan Menulis Teks Deskripsi Pada Siswa di Kelas VII-C Pada Siklus I dan Siklus II}

\begin{tabular}{|c|c|c|c|}
\hline \multicolumn{1}{|c|}{ Rentang Nilai } & Prasiklus & Siklus I & Siklus II \\
\hline $90-100$ & - & - & 9 \\
\hline $80-89$ & 4 & 5 & 9 \\
\hline $70-79$ & 2 & 11 & 11 \\
\hline$\leq 70$ & 24 & 15 & 1 \\
\hline Nilai Rata-rata Siswa Kelas VII-C & 30 & 30 & 30 \\
\hline Nilai Tertinggi & 82,33 & 68,6 & 81 \\
\hline Nilai Terendah & 40 & 85 & 90 \\
\hline Persentase Ketuntasan Klasikal & $20 \%$ & 50 & 60 \\
\hline Persentase Yang Tidak Tuntas & $80 \%$ & $63,33 \%$ & $87,67 \%$ \\
\hline
\end{tabular}


Dari tabel tersebut dapat dilihat bahwa rata-rata nilai tes siswa pada siklus I adalah 68,6. Pada siklus I siswa yang memperoleh nilai tertinggi dari 30 siswa yang mengikuti tes adalah dengan nilai 80 , sedangkan nilai terendah 50 . Hasil tes ini sudah memuaskan, karena terjadi peningkatan pada siklus II.

Pada siklus II persentase daya serap siswa mengalami peningkatan sebesar $\quad 63,33 \%$ menjadi $\quad 87,67 \%$. Artinya, siswa sudah memahami secara baik materi pelajaran yang diajarkan dan siswa dapat menulisn teks deskripsi secara baik. Ketuntasan belajar diperoleh memenuhi kriteria ketuntusan minimum (KKM) secara klaksikal SMP Negeri 3 Pancur Batu 70 dan dicapai pada siklus II tersebut melebihi standar minimum $75 \%$.

Kenaikan peningkatkan hasil tes menulis teks deskripsi siklus I dan siklus II dapat dilihat pada grafik berikut ini

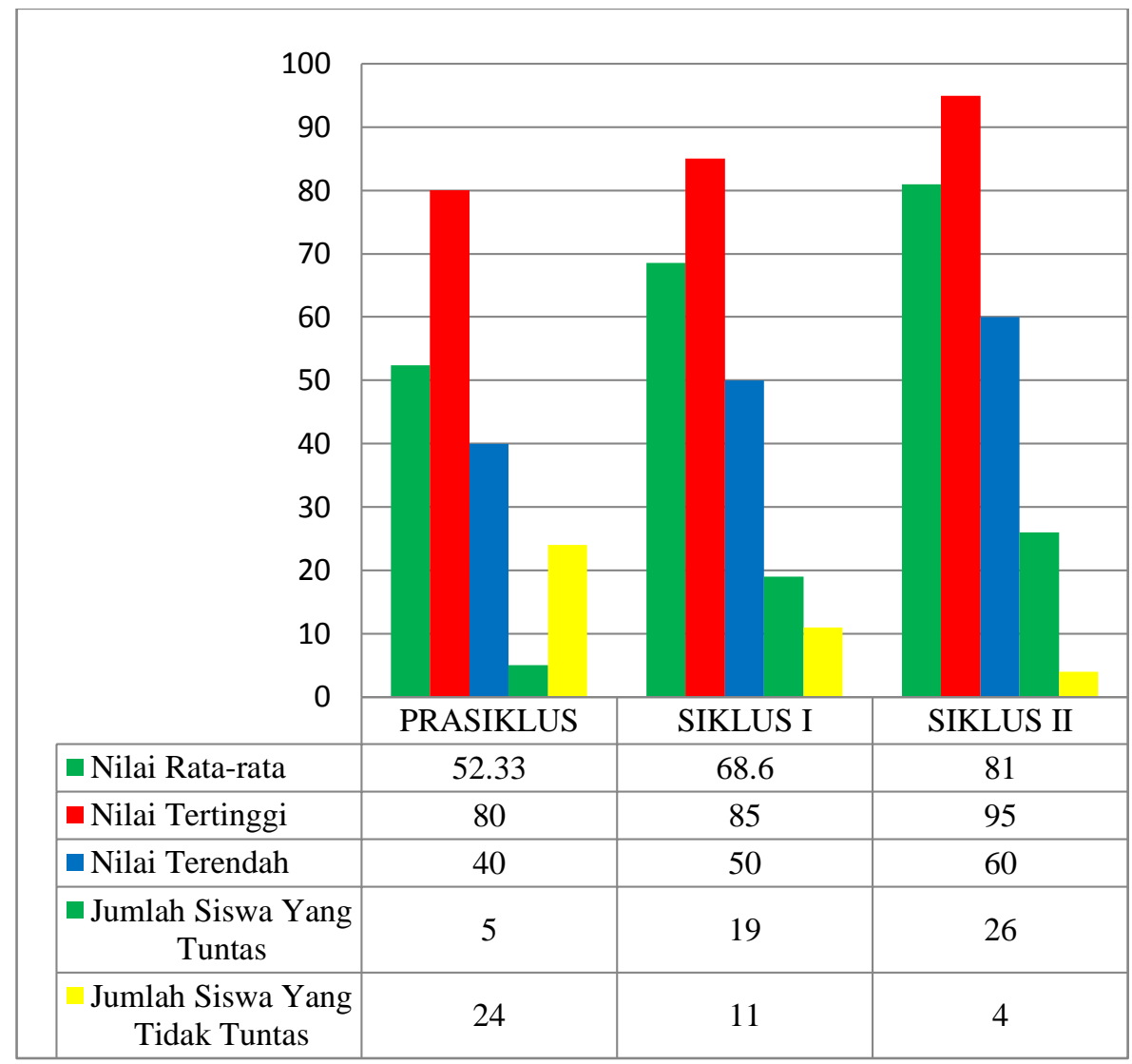

Grafik 1 Nilai Rata-rata, Keaftifan siswa, dan Ketuntasan Belajar

Dari grafik tersebut menunjukan bahwa adanya peningkatan dari sikllus I ke siklus II, berikut penjelasannya; Pada siklus I nilai rata-rata sebesar 68,6 dan terdapat peningkatan pada siklus II yaitu sebesar 81. Begitu juga dengan Keaktifan siswa, pada siklus I terdapat $63,33 \%$ yang tuntas dalam keaktifan, setelah dilanjut ke siklus II maka bertambah menjadi $81 \%$ siswa yang 
tuntas dalam hal keaktifan. Dan yang terakhir pada ketuntasan belajar, pada siklus I yang tuntas sebanyak 19 siswa atau $(36,37 \%)$ dan meningkat pada siklus II yaitu 26siswa yang tuntas atau (81\%). Peningkatan-peningkatan yang cukup baik tersebut disebabkan kelemahan-kelemahan pada siklus I berhasil diperbaiki pada siklus II. Pada peningkatan aktivitas siwa tentu saja dipengaruhi oleh faktor kemampuan peneliti sebagai guru dalam menjelaskan dan membimbing proses belajar-mengajar menulis teks fabel melalui penerapan modeldiscovery learning .

Untuk mengetahui peningkatan aktivitas dan rata-rata hasil belajar siswa dalam pembelajaran bahasa Indonesia pada siklus I dan II dapat dilihat dalam tabel berikut ini.

Tabel 2

Kualifikasi Nilai Keterampilan Menulis Teks Deskripsi Siklus I dan Siklus II (Aqib 2018: 68)

\begin{tabular}{|l|c|c|c|c|c|}
\hline No & Kualifikasi Nilai & Abjad & Siklus I & Siklus II & Penilaian \\
\hline 1 & $100-85$ & $\mathrm{~A}$ & 3 & 17 & Baik sekali \\
\hline 2 & $84-70$ & $\mathrm{~B}$ & 7 & 9 & Baik \\
\hline 3 & $69-55$ & $\mathrm{C}$ & 5 & 2 & Cukup \\
\hline 4 & $54-40$ & $\mathrm{D}$ & 15 & 2 & Kurang \\
\hline 5 & $39-0$ & $\mathrm{E}$ & 0 & 0 & Sangat kurang \\
\hline
\end{tabular}

Tabel 3.Peningkatan Penilaian Afektif Siswa Siklus I dan Siklus II

\begin{tabular}{|l|l|c|c|}
\hline No & \multicolumn{1}{|c|}{ Aktivitas } & $\begin{array}{c}\text { Jumlah Siswa } \\
\text { Siklus I }\end{array}$ & $\begin{array}{c}\text { Jumlah siswa } \\
\text { Siklus II }\end{array}$ \\
\hline 1. & Ketepatan waktu dalam menyelesaikan tugas & 15 & 28 \\
\hline 2. & Kerja sama & 16 & 24 \\
\hline 3. & Tanggung jawab & 15 & 27 \\
\hline 4. & Minat terhadap materi & 20 & 31 \\
\hline 5. & Keaktifan dalam diskusi & 19 & 28 \\
\hline 6. & Mampu mengungkapkan pendapat & 5 & 25 \\
\hline 7. & Menghargai/ menghormati pendapat orang lain & 12 & 30 \\
\hline 8. & $\begin{array}{l}\text { Menggunakan tata bahasa dalam menjawab } \\
\text { pertanyaan }\end{array}$ & 3 & 24 \\
\hline 9. & Keseriusan dalam menelaah soal & 6 & 28 \\
\hline 10 & Mampu mendeskripsikan materi yang dibahas & 5 & 28 \\
\hline
\end{tabular}


Berdasarkan data tersebut dapat dilihat peningkatan aktivitas belajar siswa pada siklus I dan siklus II. Yang berdampak pada proses dan hasil belajar, dengan menerapkan model pembelajaran discovery learning.

Dari analisis data dan hasil penelitian siklus I dan II diketahui bahwa terjadi peningkatan kualitas belajar dalam keterampilan menulis teks deskripsi dengan menerapkan model discovey learning. Peningkatan ini terjadi pada aktivitas dan hasil tes akhir siswa secara keseluruhan.

\section{SIMPULAN DAN SARAN}

\section{a. KESIMPULAN}

Peningkatan hasil pembelajaran menulis teks deskripsi dengan menerapkan model Discovery Learning pada siswa kelas VII-C SMP Negeri 3 Pancur Batu tahun pelajaran 2018/2019

Terdiri dari atas tiga proses:

1. Kualitas proses pembelajaran keterampilan menulis teks deskripsi siswa kelas VII-C SMP Negeri 3 Pancur Batu pada prasiklus siswa kurang dalam menulis teks deskripsi. Dengan penerapan model Discovery Learning yang diberikan pada siklus I dan siklus II dapat meningkatkan hasil belajar siswa. Siswa tidak takut untuk berpendapat, siswa lebih giat dalam membaca, siswa lebih giat untuk mengulang kembali materi yang telah diberikan oleh guru, sehingga hasil dari penerapan model pembelajaran Discovery Learning dapat meningkatkan keterampilan menulis teks deskripsi.

2. Kualitas hasil keterampilan menulis teks deskripsi siswa kelas VII-C SMP Negeri 3 Pancur Batu,pada prasiklus ketuntasan klasikal $16,67 \%$, dan nilai rata-rata siswa mencapai 52,33. Hasil penilaian tes keterampilan menulis teks deskripsi siklus I ketuntasan klasikal 36,67\%, dan nilai rata-rata siswa mencapai 68,6. Pada siklus II model discovery learningdapat meningkatkan keterampilan menulis teks deskripsi siswa dengan perolehan nilai rata-rata siswa yang mencapai 81 dan persentase ketuntasan klasikal siswa memperoleh $86,67 \%$.

3. Peningkatan hasil pembelajaran keterampilan menulis teks deskripsi dengan menerapkan model discovery learning telah meningkat. Terbukti dari hasil penelitian nilai rata-rata prasiklus 52,33 meningkat kembali nilai rata-rata siswa siklus I 68,6 dan meningkat kembali nilai rata-rata siswa siklus II 81 . Oleh karena itu, model discovery learning pada bidang studi Bahasa Indonesia dengan sub pokok pembahasan materi pembelajaran menulis sangat berperan penting untuk meningkatkan keterampilan menulis teks deskripsi siswa dan mampu memberikan motivasi serta kesenangan siswa dalam proses pembelajaran menulis teks deskripsi yang terkadang membuat siswa jenuh atau bosan sehingga siswa dapat lebih aktif dan lebih bersemangat dalam proses pembelajaran menulis teks deskripsi menggunakan model discovery learning dengan konsep bermain sambil belajar.

\section{b. SARAN}

Berdasarkan kesimpulan hasil penelitian yang telah dipaparkan tersebut, peneliti memberikan beberapa saran sebagai berikut.

1. Untuk Guru

Guru bidang studi Bahasa Indonesia di kelasVII-CSMP Negeri 3 Pancur Batu, disarankan dengan adanya 
penelitian ini secara bertahap dapat mengetahui startegi pembelajaran yang bervariasi. Salah satu model yang baik digunakan adalah Discovery Learning.

2. Untuk Siswa

Siswa di kelasVII-CSMP Negeri 3 Pancur Batu, disarankan supaya lebih sering melatih kemampuan menulis agar cepat dan tanggap dalam menilai sebuah informasi pesan dan tidak boleh segan meminta bimbingan guru.

3. Untuk Sekolah

Penelitian ini disarankan untuk pihak sekolah agar dapat memberikan sumbangan yang positif dalam pembelajaran Bahasa Indonesia khususnya Kemampuan menulis teks deskripsi diSMP Negeri 3 Pancur Batu sehingga dapat meningkatkan kemampuan menulis siswa.

4. Untuk Peneliti

Peneliti dalam bidang pendidikan dan bahasa disarankan untuk menjadikan penelitian ini sebagai bahan referensi dan pertimbangan untuk dikembangkan pada penelitian selanjutnya mengenai pembelajaran kemampuan menulis teks deskripsidengan menggunakan model discovery learning.

\section{DAFTAR PUSTAKA}

Arikunto, Suharsimi. 2003. Penelitian Tindakan Kelas. Makalah disajikan dalam Diklat Pengembangan Profesi dan Jabatan Fungsional Guru, Direktorat Tenaga Kependidikan Dasar dan Menengah, Ditjen Dikdasmen, Diknas.

Bidinigsih,C.Asri. 2005. Belajar dan pembelajaran. Jakarta: Rineka Cipta

Berlin. Sani. 2014. Strategi Pembelajaran Di Dalam Kelas. Alfabeta: Bandung

Dalman. (2010). Mata Kuliah: Menulis. Bandar Lampung: UM Lampung
Kemmis, S. 1982. Action Research in Retropect and Prospect. In C. Henry, C. Cook, Kemmis, R.Mc Taggart (eds), The Action Research Rearder Action Research and the Critical Analysis of pedagogy. Geelong: Deakin University

Pariah. 2018. Jurnalistik Pendidikan Bahasa Dan Sastra Indon Esia (Pembelajaran Menulis Teks Deskripsi:Pada Siswa Kelas VII SMP Negri 10 Bandar Tanjung

Riska Juliyanti, Lilih Suryani. Jurnalistik Pendidikan Bahasa dan Sastra Indonesia: Pembelajaran Menulis Teks Deskripsi dengan menggunakan Metode Discovery Learning.

Suparno dan Yunus, M. (2008).Keterampilan Dasar Menulis. Jakarta: Universitas Terbuka.

Sugiyono.(2009). Metode Penelitian Pendidikan. Bandung: Alfabeta.

Sugiyono. 2014. Metode pendekatan kuantitatif, kualitatif dan $R \& D$ :Alfabeta, CV: Bandung

Tarigan, Henry Guntur $1980^{2}$. Membaca Sebagai suatu Keterampilan Berbahasa.

Bandung: FKSS -IKIP.

Tarigan, Hendry Guntur. (2005). Menulis sebagai Kerampilan Berbahasa. Bandung: Angkasa.

Tarigan, Djago. (2009). Membina Keterampilan Menulis Paragraf dan Pengembangannya, Bandung: Angkasa.

Yossy Idris, Harris Effendi Thahar, Novia Juita (2011-2012), Jurnal Bahasa, Sastra dan Pembelajaran. Peningkatan keterampilan menulis karangan deskripsi melalui metode discovery learning: Universitas Ekasakti Padang 